\title{
Psicoanálisis lacaniano, retórica y teoría gramsciana: tres homologías de la hegemonía y sus usos ónticos en la dinámica política en la Teoría del Discurso de Laclau
}

Lacanian psychoanalysis, rhetoric and Gramscian theory: three homology concepts of Hegemony and their ontic usages in the political dynamic within the Discourse theory of Laclau

Hernán Fair ${ }^{1}$

Resumen: Este trabajo analiza las homologías que construyó la Teoría Política del Discurso de Ernesto Laclau para conceptualizar la noción de hegemonía y sus usos óntico-fenoménicos en la dinámica históricopolítica. Se argumenta que, desde el plano ontológico, Laclau conceptualiza la lógica discursiva de la hegemonía a nivel general mediante tres homologías basadas en figuras de la retórica (el desplazamiento de la metonimia a la metáfora), el psicoanálisis lacaniano (el desplazamiento del objeto pequeño a a la Cosa) y la teoría de la hegemonía de Gramsci (el desplazamiento de la clase corporativa a la clase hegemónica). Desde el nivel óntico-fenoménico, Laclau pone en juego esta

1 Doctor en Ciencias Sociales (UBA). Investigador Adjunto del CONICET. Profesor e Investigador en la Universidad Nacional de Quilmes, con sede de trabajo en el Centro IESAC. 
conceptualización en la dinámica política para mostrar la mutua implicación y contaminación discursiva entre lo particular y lo universal, la historicidad y contingencia de las lógicas y las identidades colectivas, y la tensión constitutiva y el compromiso inestable entre equivalencia y diferencia, que caracterizan a la operación hegemónica.

Palabras clave: Teoría de la hegemonía; Objeto a; Metonimia; Desplazamiento discursivo; Operación hegemónica.

Abstract: This paper analyzes the homologies constructed by Ernesto Laclau's Political Theory of Discourse to conceptualize the notion of hegemony and its ontic-phenomenological uses in historical-political dynamics. It is argued that, from the ontological level, Laclau conceptualizes the discursive logic of hegemony at a general level through three homologies based on figures of rhetoric (the displacement from metonymy to metaphor), Lacanian psychoanalysis (the displacement from object a to the Thing) and Gramscian theory of hegemony (the displacement from corporative class to the hegemonic class). From the ontic-phenomenal level, Laclau shows in political dynamic the mutual implication and discursive contamination between particular and universal, the contingency and historicity of logics and collective identities, and the constitutive tension and unstable compromise between equivalence and difference, that characterizes the hegemonic operation.

Keywords: Theory of hegemony; Object a; Metonymy; Discursive displacement; Hegemonic operation. 


\section{Introducción}

La noción gramsciana de hegemonía tuvo un fuerte impacto en la elaboración de la Teoría Política del Discurso (TPD) de Ernesto Laclau. Como señala Laclau, "la teoría del discurso fue concebida en el análisis político como una perspectiva vinculada a la noción de hegemonía" (Laclau, 2003a: 1). En ese marco, Laclau define a la hegemonía como "una categoría central para una teorización de la política" (Laclau, 1998: 97) y como una "categoría central del análisis político" (Laclau, 2006: 60). La bibliografía especializada examinó las definiciones de hegemonía en la teoría política de Laclau y los vínculos y tensiones que existen entre su ontología política del discurso y los aspectos ónticos en los que se inviste ${ }^{2}$. Sin embargo, hasta el momento no se analizaron detenidamente las homologías que construyó la teoría del discurso y las identidades políticas de Laclau para conceptualizar y poner en juego a la hegemonía desde su doble acepción óntica y ontológica. El presente trabajo se propone echar un poco de luz sobre esta cuestión. De este modo, procuramos contribuir a fortalecer la discusión teórico-política en el campo de la izquierda posmarxista, la teoría política contemporánea y los estudios políticos posfundacionales.

2 Sobre estas intensas discusiones y polémicas, puede verse Fair (2014, 2016, 2019). 


\section{Tres homologías transdisciplinarias en la teoría discursiva de la hegemonía de Laclau}

\subsection{La homología con los tropos clásicos de la retórica (metonimia y metáfora)}

Como señalan Glynos, Howarth, Norval y Speed (2009), la Teoría Política del Discurso ("Political Discourse Theory") de Laclau parte de la base que "las funciones discursivas como horizonte ontológico, y sus significados y prácticas -y cualquier otro objeto que pueda ser calificado como significativo- son por definición de carácter discursivos" (Glynos, Howarth, Norval y Speed, 2009: 9). Para explicar la lógica político-discursiva de universalización parcial de lo particular que caracteriza a la hegemonía, Laclau construyó en sus principales textos una serie de homologías transdisciplinarias. Una primera homología que observamos se basó en el uso de tropos clásicos de la retórica. El empleo de estas figuras como constitutivas de lo social se encuentra presente desde su primera etapa posfundacional, que se inicia en sus trabajos de la primera mitad de los años ochenta. Según Laclau, sinonimia, metonimia y metáfora:

No son formas de pensamiento a través de las cuales las relaciones sociales se constituirían, sino que son parte del terreno primario mismo de constitución de lo social (Laclau y Mouffe, 2004: 150).

Enfocándose en los tropos clásicos de la metonimia y la metáfora, el teórico político destacó que la hegemonía representa una lógica "esencialmente metonímica" (Laclau y Mouffe, 2004: 186). Pero, a su vez, señaló que "la fijación de lo social" debe ser entendida como "metafórica"3 (Laclau

3 Las figuras de la metáfora y la metonimia fueron analizadas también por el 
y Mouffe, 2004: 151, 169). En trabajos posteriores Laclau sostuvo que la TPD podía ser entendida en términos de una "retórica generalizada", a partir de "procesos tropológicos" guiados por un desplazamiento contingente y constante entre las cadenas equivalenciales y diferenciales mediante "combinaciones" (que remiten a metonimias) y "sustituciones" (que refieren a metáforas):

Para la teoría del discurso la vida social puede ser descripta en términos de una retórica generalizada: como ninguna identidad está cerrada en sí misma, pero es capaz de asumir constantes desplazamientos en términos de combinaciones y sustituciones, ellas están constituidas a través de procesos esencialmente tropológicos, los cuales no refieren a ninguna fundación trascendental última (Laclau, 2003a: 6).

En un trabajo intitulado "Política de la retórica" [publicado en español en el año 2002 y reeditado en su libro póstumo del 2014] Laclau profundizó en los aportes de la retórica para la teoría política y el análisis político-discursivo. En este texto Laclau sostuvo, a partir de contribuciones de Paul De Man (1996) y Gérard Genette (1989), que existe una homología entre la lógica discursiva de desplazamiento particular-universal de la hegemonía y el "movimiento político-tropológico generalizado" de la retórica:

Ya están lejos los tiempos en que la transparencia de los actores sociales, de los procesos de representación, incluso de las presuntas lógicas subyacentes al tejido social, podría ser aceptada de forma

psicoanálisis lacaniano, a partir de la influencia de la lingüística de Jakobson (Lacan, 2003: 64, 419, 485 y 487). Laclau reconoce los aportes de Jakobson (Laclau, 2014b: 75-77), destaca la redefinición lacaniana de las nociones freudianas de condensación y desplazamiento (Laclau, 2014b: 84) y se enfoca en los aportes de De Man y Genette (Laclau, 2006, 2014b). Sobre el empleo de categorías de la retórica en la teoría política de Laclau y sus posibles usos en el Análisis Político del Discurso, véanse Hillis Miller (2004), Buenfil Burgos (2009) y Glynos, Howarth, Norval y Speed (2009: 13-17). Para otros usos de estas figuras retóricas en el análisis político, véase Lakoff y Johnson (1998). 
no problemática. Cada institución política, cada categoría de análisis político, se nos presenta hoy día como el locus de juegos de lenguaje indecidibles. El carácter sobredeterminado de toda diferencia o identidad política abre el espacio de un movimiento tropológico generalizado y revela así cuán fructífero resulta el proyecto intelectual de De Man para el análisis ideológico y político. En mis trabajos, este movimiento político-tropológico generalizado ha sido denominado hegemonía (Laclau, 2006: 59-60).

En estos textos Laclau enfatizó en la lógica de desplazamiento retórico-político como constitutiva de lo social, en tanto "toda instancia discursiva se constituye a través de desplazamientos tropológicos" (Laclau, 2002: 1). Y sostuvo que la hegemonía no es sólo "metonímica", sino que genera un "desplazamiento catacrético" (Laclau, 2003b: 86, 2005: 96). Ello le permite asumir la forma de una "analogía" o de una "metáfora" de la "totalidad ausente" 4 (Laclau, 2005: 141, 2006: 75, 2008: 96). En ese sentido, la hegemonía se caracteriza por realizar un movimiento tropológico en el que la relación metonímica "tiende a la totalización metafórica" (Laclau, 2006: 78). No obstante su intento de totalización, ninguna operación hegemónica puede eliminar su carácter metonímico (particular) y contingente, inherente a la propia noción de hegemonía:

Toda hegemonía intenta retotalizar y hacer tan necesarios como sea posible los vínculos contingentes en que su poder articulador está basado. En tal sentido, ella tiende a la totalización metafórica. Esto es lo que le da su dimensión de poder. Es un poder, sin embargo, que conserva las huellas de su contingencia y es, en tal sentido, esencialmente metonímica (Laclau, 2006: 78).

4 Laclau (2006) también menciona el ejemplo del Cero y el Uno de De Man (p. 63 y ss.), aunque luego reconoce que "mientras que en la hegemonía hay una libre variación en lo que se refiere al elemento que ocupa la posición hegemónica, en el caso del cero no tenemos una tal latitud de maniobra: el cero sólo puede ser un uno. En tal caso no se trataría, estrictamente, de una metonimia, sino de una catacresis" (p. 75). 
De este modo, Laclau encuentra en las figuras clásicas de la metonimia y la metáfora la misma lógica discursiva de desplazamiento tendencial y de "mutua implicación" (Laclau, 2014b: 72) entre lo particular y lo universal que caracterizan a la forma hegemónica. Este desplazamiento y contaminación recíproca remite, a su vez, a la "tensión" constitutiva que existe entre la "lógica de la equivalencia" y la "lógica de la diferencia", en el que la primera subvierte a la segunda, aunque sin eliminarla (en caso contrario, se disolvería el propio concepto de hegemonía). Como lo deja en claro Laclau en "La razón populista":

Lo que hemos demostrado es que la equivalencia y la diferencia son finalmente incompatibles entre sí: sin embargo, se necesitan la una a la otra como condiciones necesarias para la construcción de lo social. Lo social no es otra cosa que el locus de esta tensión insoluble (Laclau, 2005: 106-107).

La equivalencia es precisamente lo que subvierte la diferencia, de manera que toda identidad es construida dentro de esta tensión entre la lógica de la equivalencia y la lógica de la diferencia (Laclau, 2005: 94).

En otro trabajo del mismo período Laclau reafirma esta idea, al sostener que entre la lógica de la equivalencia y la lógica de la diferencia existe una "dialéctica compleja" y un "compromiso inestable". Ello presupone la presencia y tensión entre ambas lógicas político-discursivas en las situaciones históricas concretas:

La equivalencia es, claramente, una forma de articular diferencias. Hay, por tanto, entre la equivalencia y la diferencia, una dialéctica compleja, un compromiso inestable. Existe una variedad de situaciones históricas que presuponen la presencia de ambas, pero al mismo tiempo, su tensión (Laclau, 2009: 67).

De un modo análogo a la tensión particular-universal que caracteriza a la operación hegemónica (Laclau, 1996), 
Laclau muestra que, desde el "proceso de retorización general" (Laclau, 2006: 92), existe una tensión constitutiva entre las figuras de la metonimia y la metáfora, que se sobredeterminan mutuamente al desplazarse al análisis de la dinámica política.

En su última etapa, además, Laclau profundizó en el uso de figuras complementarias de la retórica clásica como constitutivas para el análisis político-discursivo. En "La razón populista" (LRP) el historiador argentino se refirió a la figura de la catacresis como un concepto homólogo a la forma de universalidad (relativa) de los significantes vacíos en la operación hegemónica (Laclau, 2005: 96). A continuación, Laclau distinguió entre la metonimia y la sinécdoque y destacó el aporte de esta última figura (la parte que representa al todo) para analizar la lógica de desplazamiento tendencial particular-universal-particular de la relación hegemónica (Laclau, 2005: 97). En otro texto Laclau sostuvo que las figuras de la sinécdoque y la analogía, al romper con la literalidad del sentido, muestran que la parte no puede eliminar al todo, ni el todo a la parte, sin que la misma noción de hegemonía se disuelva como tal. De este modo, el movimiento tropológico contingente y la lógica discursiva de deslizamiento incesante de las figuras en la dinámica política muestran que los tropoi tienden a diluirse entre sí y a perder su especificidad taxativa:

Las condiciones de una retórica cuyos movimientos tropológicos han de ocupar el terreno de un fundamento que no es él mismo fundado han de encontrarse en la imposibilidad de aceptar la definición literal de cada uno de los tropoi, y en la necesidad de subrayar las lógicas por las cuales cada uno de ellos tiende a diluirse en el otro. Lo mismo ocurre con la hegemonía: las condiciones de su plena operatividad son las mismas que las condiciones de su extinción (Laclau, 2006: 93). 
En este sentido, el hecho de aceptar la literalidad del sentido en su grado cero sería homólogo a aceptar un orden totalitario o con algún tipo de fundamento o esencia de lo social. Estos aspectos son contrarios y antitéticos a la lógica de universalidad relativa, precaria y parcial que define a la hegemonía y al carácter socialmente construido, histórico y contingente de lo social.

\subsection{La homología con conceptos nodales del psicoanálisis lacaniano (el objeto a y la Cosa)}

Una segunda homología de la noción gramsciana de hegemonía que construyó la Teoría Política del Discurso de Laclau proviene del uso de conceptos nodales del psicoanálisis lacaniano. El empleo de herramientas propias de la teoría lacaniana es una constante de la perspectiva laclauiana. En una primera etapa, a partir del abordaje de la lógica del significante (S/s), la tesis de la "imposibilidad de la sociedad" (análogo a la "ausencia de relación sexual" de Lacan) y conceptos lacanianos clave como "cadena significante" (redefinido como "cadena de equivalencias"), "punto nodal", "sutura" y lo "Real" (Laclau y Mouffe, 2004). En trabajos posteriores Laclau incluyó referencias a lo imaginario, las fantasías, el goce, la ligazón catexial y los anudamientos entre lo imaginario, lo simbólico y lo Real ${ }^{5}$ (Laclau 1993, 1996, 2003a, 2005, 2008).

A partir de LRP Laclau profundizó en el uso de conceptos lacanianos desde el campo de la teoría política posfundacional, enfatizando en sus homologías con la forma de desplazamiento discursivo de la hegemonía. En

5 Sobre los vínculos entre las teorías del discurso de Lacan y Laclau y sus usos para el análisis sociopolítico y crítico, véanse los esclarecedores trabajos de Stavrakakis (2007a, 2007b) y Glynos y Stavrakakis (2004). 
este texto Laclau afirmó que la lógica de universalización (parcial) que caracteriza a la operación hegemónica resulta idéntica a la lógica de universalización de lo particular del "objeto a" lacaniano. Recordemos que para Lacan todo sujeto se encuentra "dividido" o "tachado" (\$) por efecto del lenguaje (Lacan, 1987: 207). La función del "objeto a" u objeto petit a (pequeño a) consiste en "tapar la hiancia que constituye la división inaugural del sujeto" (Lacan, 1987: 278). En el Seminario 7 Lacan (1990) sostiene que, en los mecanismos exitosos de sublimación, los objetos a, en tanto objetos imaginarios, logran simbolizar el fantasma (fantasía primordial) de unidad plena y son elevados a la "dignidad de la Cosa", al recubrir la falta constitutiva del sujeto 6 .

En LRP Laclau se refirió al objeto a como "la categoría ontológica principal" de la teoría lacaniana. Luego, destacó que la hegemonía supone el "mismo descubrimiento" (y no uno meramente análogo) en el modo de alcanzar la imposible "plenitud social" que dicha perspectiva. Esto se debe a que la teoría de Lacan comparte con la operación hegemónica la misma lógica de "investidura" en un "objeto parcial" que es "elevado" a la "dignidad de la Cosa". El objeto pequeño a representa una particularidad, pero asume el rol de la universalidad de lo social. Esta universalización es ilusoria, ya que supone el sueño de encarnar una "totalidad mítica" madre/hijo (el acceso imposible a la Madre-Cosa), o su

6 En palabras de Lacan: “El mecanismo de sublimación (...) debe buscarse en una función imaginaria, muy especialmente aquella para la cual nos servirá la simbolización del fantasma (\$a), que es la forma en que se apoya el deseo del sujeto. En formas históricamente, socialmente, específicas, los elementos a, elementos imaginarios del fantasma, llegan a recubrir, a engañar al sujeto, en el punto mismo de Das Ding" (Lacan, 1990: 123). Cabe destacar que en este trabajo nos enfocamos en la interpretación de Laclau sobre el objeto a, más allá del abordaje que realiza Lacan. Sobre los usos y ambigüedades de la noción de objeto petit a en la obra de Lacan, véanse Dor (1997), Zizek (1992, 2005), Stavrakakis (2007a, 2007b). 
correlato político, la sociedad "reconciliada consigo misma". En palabras de Laclau:

Si la plenitud de la madre primordial es un objeto puramente mítico, no hay ningún goce alcanzable, excepto a través de la investidura radical en un objeto a. Así, el objeto a se convierte en la categoría ontológica principal. Pero podemos llegar al mismo descubrimiento (no uno meramente análogo) si partimos del ángulo de la teoría política. No existe ninguna plenitud social alcanzable excepto a través de la hegemonía; y la hegemonía no es otra cosa que la investidura, en un objeto parcial, de una plenitud que siempre nos va a evadir, porque es puramente mítica. La lógica del objeto a y la lógica hegemónica no sólo son similares: son simplemente idénticas (Laclau, 2005: 148-149).

En otro pasaje de LRP Laclau refuerza la idea de identidad vis a vis entre ambas lógicas discursivas, dando centralidad al concepto lacaniano de objeto petit a:

El conjunto de la lógica del objeto petit a que, como dijimos, es idéntica a la lógica hegemónica (Laclau, 2005: 291).

Al afirmar que ambas lógicas políticas "son simplemente idénticas", Laclau homologó la forma de universalidad relativa de la hegemonía con la lógica discursiva por la cual se produce un "investimento" o "investidura catexial" en un objeto parcial $u$ "objeto a" que encarna la (imposible) plenitud de la "Cosa":

El único horizonte totalizador posible está dado por una parcialidad (la fuerza hegemónica) que asume la representación de una totalidad mítica. En términos lacanianos: un objeto es elevado a la dignidad de la Cosa (Laclau, 2005: 149).

En LRP Laclau también incluyó al objeto parcial como un elemento constitutivo de la teoría del populismo, de manera tal que sostuvo que:

No hay populismo posible sin una investidura afectiva en un objeto parcial ${ }^{7}$ (Laclau, 2005: 149).

7 Aunque excede el marco de este trabajo, el hecho de que Laclau sitúe al objeto 
En Debates y combates Laclau (2008) retomó esta homología vis a vis entre la forma político-discursiva de universalidad relativa de la relación hegemónica y la elevación del objeto pequeño a (como elemento particular) a la Cosa (como universalidad imposible) en la teoría lacaniana:

El punto relevante para nuestro tema es que lo pleno, la Cosa freudiana, es inalcalzable; es tan sólo una ilusión retrospectiva que es sustituida por objetos parciales que encarnan esa totalidad imposible. En palabras de Lacan: la sublimación consiste en elevar un objeto a la dignidad de la Cosa. Como he intentado mostrar, la relación hegemónica reproduce todos esos momentos estructurales: una cierta particularidad asume la representación de una universalidad que siempre se aleja (Laclau, 2008: 20).

En otros trabajos de esta última etapa Laclau volvió a referirse a la centralidad del objeto a y destacó su relación de homología con la lógica hegemónica. En el artículo "Antagonismo, subjetividad y política" (publicado en su primera edición en español en 2012 en la revista Debates y combates) Laclau se refiere al "objeto a lacaniano" como "un objeto parcial que asume, sin embargo, el rol de la totalidad" (Laclau, 2014a: 147). Ello implica, en palabras de Lacan, "elevar un objeto a la dignidad de la Cosa". Sin embargo, se trata de un "objeto imposible", en tanto el acceso pleno a la "Cosa", como símbolo de la universalidad plena, es inalcanzable estructuralmente (Laclau, 2014a: 148).

En otro texto de su libro póstumo, "Articulación y los límites de la metáfora" (publicado en su primera edición

a como un elemento constitutivo de la teoría del populismo, idéntico al rol de los significantes vacíos en la operación hegemónica, entra en tensión con la supuesta centralidad de la figura del líder populista que varios analistas laclauianos le indilgan a su teoría de la hegemonía. Sobre este problema, véanse las valiosas contribuciones de De Ípola (2009) y Melo y Aboy Carlés (2014: 416-418). 
en inglés en 2008 y en una primera versión en español en la revista Studia politicae en 2010), Laclau (2014b) profundizó en esta misma homología. A partir del uso de la palabra "idéntica", el teórico político mostró la identificación vis a vis que existe entre la lógica discursiva de desplazamiento (tendencial) de la hegemonía y la lógica del objeto pequeño a:

Este proceso por el cual las identidades dejan de ser puramente inmanentes a un sistema y requieren una identificación con un punto trascendente a este sistema

-que es lo mismo que decir: cuando una particularidad se convierte en el nombre de una universalidad ausente- es lo que llamamos hegemonía. Su lógica es idéntica a la del objeto a" (Laclau, 2014b: 86).

Debido a que "La función ontológica del objeto a es trascender su particularidad óntica y ser la encarnación de la Cosa, de la imposible totalidad" (Laclau, 2014a: 148), se produce, como subraya Laclau en el prefacio a la edición inglesa de su último libro, una "homología profunda" entre la noción gramsciana de hegemonía y la lógica del objeto petit a de Lacan:

Numerosos aspectos de la obra de Lacan fueron para mí de vital importancia, en especial la lógica del objeto a, en la que inmediatamente percibí su homología profunda con la hegemonía gramsciana (Laclau, 2014c: 19).

Para Laclau, el objeto a-la Cosa y la operación hegemónica comparten desde el plano ontológico una misma lógica discursiva de desplazamiento (tendencial) de lo particular a lo universal para encarnar una universalidad que, necesariamente, es relativa y precaria ("no toda", en los términos lacanianos -Lacan, 2008: 15 y ss.-). En el caso de la hegemonía, porque el hecho de eliminar los antagonismos, triturar las diferencias y particularidades constitutivas supondría destruir esta misma categoría 
para asumir una forma fundamentalista o esencialista. En el caso del objeto a, debido a que la Cosa (el cuerpo de la madre, en tanto prohibido y perdido) es inalcanzable, la alteridad es constitutiva y no existe ninguna plenitud de lo social. En ambos ejemplos el desplazamiento (tendencial) de lo particular hacia lo universal nunca abandona el resto de particularismo. De este modo, sólo desde una "lógica fantasmática" (Glynos, Howarth, Norval y Speed, 2009: 11) un elemento particular puede suponer el acceso a una universalidad plena y transparente.

\subsection{La homología conceptual con la teoría gramsciana (la clase corporativa y la clase hegemónica)}

Fuertemente influido por las contribuciones de Antonio Gramsci (2008a, 2008b), Laclau sostuvo en sus trabajos de la primera mitad de los años ochenta que "hegemonía es el concepto fundamental de la teoría política marxista" (Laclau, 1985: 19). El historiador argentino destacó en esta etapa la "divisoria de aguas gramsciana" como un aporte central para pensar un concepto más "complejo" de hegemonía. Al mismo tiempo, se propuso construir "una nueva concepción de la política fundada en la noción de hegemonía" (Laclau, 1985: 34). Para realizar esta conceptualización Laclau tuvo en cuenta una serie de transformaciones sociohistóricas medulares de las últimas décadas del siglo XX, caracterizadas por la crisis del Estado de Bienestar y del modelo de producción fordista, el declive de la clase obrera tradicional, la emergencia de nuevos movimientos sociales y el surgimiento de un capitalismo pos-industrial (Giacaglia, 2012: 94). En el marco de estas profundas transformaciones en las identidades políticas y en la estructura económica 
y social, en "Hegemonía y estrategia socialista" Laclau realizó -junto con su esposa Mouffe- una deconstrucción genealógica de la noción gramsciana de hegemonía en clave anti-esencialista y construyó una concepción teórica y ontológica más compleja para el análisis político ${ }^{8}$ (Laclau y Mouffe, 2004: 99 y ss.).

Laclau mantuvo en el transcurso de su obra una fuerte influencia de la teoría política gramsciana. Incluso, reconoció que "Nuestro trabajo puede ser visto como una extensión de la obra de Gramsci" (Laclau, 1993: 205). En el prefacio a la edición en inglés de su último libro, Laclau (2014c) sostuvo que, para alguien que, como él, venía de la militancia política en el marxismo 9 , la teoría de Gramsci significó una influencia decisiva para profundizar la comprensión de las identidades colectivas:

Gramsci proveía un nuevo arsenal de conceptos -guerra de posición, voluntades colectivas, liderazgo intelectual y moral, estado integral y, sobre todo, hegemonía- que hacía posible avanzar en la comprensión de las identidades colectivas hasta un punto que ningún otro marxista de su tiempo y, en verdad, también del nuestro, alcanzaría (Laclau, 2014c: 16).

Teniendo en cuenta la fuerte influencia de la teoría de la hegemonía de Gramsci en Laclau y sus críticas por conservar un "último reducto esencialista" (Laclau y Mouffe, 2004: 112), caracterizamos a su enfoque como posgramsciano en un sentido estricto (Fair, 2016), en consonancia con otros exponentes de este enfoque (Norval, 2008: 197).

En el marco de su innovadora concepción posgramsciana, el historiador argentino edificó una tercera homología para

8 Sobre los vínculos conceptuales entre las teorías de Laclau y Gramsci, véase Cavalcanti Alves (2010).

9 Sobre la trayectoria histórica de Laclau como militante político y sus vínculos y polémicas intelectuales y políticas con la tradición marxista, véase Melo y Aboy Carlés (2014: 396-403). 
explicar, a nivel general, la lógica de funcionamiento de la hegemonía. Para ello, retomó la distinción de Gramsci entre "clase corporativa" y "clase hegemónica", similar al desplazamiento discursivo de lo particular a lo universal de la forma hegemónica:

A la clase hegemónica se opone la clase corporativa, que representa intereses sectoriales en el seno de una totalidad suturada. La clase hegemónica, por el contrario, universaliza de algún modo sus propios objetivos, que pasan así a constituir aquellos de fuerzas sociales mucho más vastas (Laclau, 2014a: 148).

En contraste con la crítica realizada en Hegemonía y estrategia socialista, en LRP Laclau sostiene que la lógica de desplazamiento histórica de la clase corporativa a la "fuerza hegemónica" en la teoría gramsciana realiza una "ruptura epistemológica" -a la que define como "crucial" - que "rompe decisivamente" con la "lógica social esencialista" y economicista del marxismo ortodoxo ${ }^{10}$. Al mismo tiempo, Laclau reafirma su tesis que esta lógica de desplazamiento particular-universal, propia de la operación hegemónica, es homóloga a la lógica de universalización discursiva de los objetos parciales elevados a la "dignidad de la Cosa" de la teoría lacaniana:

10 Según Laclau (1993), en los textos de Marx existe una contradicción entre una concepción determinista y mecanicista que opone lógicamente a las "fuerzas productivas" y las "relaciones de producción"; y una concepción historicista de lo social, que sostiene que la "lucha de clases" es el motor de la historia. La primera concepción reenvía principalmente al "Prólogo a la contribución a la crítica de la economía política" de Marx. En este texto el pensador alemán afirma que "En un estadio determinado de la sociedad, las fuerzas productivas materiales de la sociedad entran en contradicción con las relaciones de producción existentes" (Marx, 1997, op. cit., p. 67). La segunda cosmovisión se condensa en la famosa frase del "Manifiesto comunista", cuando Marx sostiene que "La historia de todas las sociedades que han existido hasta nuestros días es la historia de las luchas de clases" (Marx y Engels, 2001, op. cit., p. 29). 
Es por esto que, dentro de la tradición marxista, el momento gramsciano representa una ruptura epistemológica tan crucial: mientras que el marxismo tradicionalmente había soñado con el acceso a una realidad sistemáticamente cerrada (la determinación en última instancia por la economía, etc.), el enfoque hegemónico rompe decisivamente con esa lógica social esencialista. El único horizonte totalizador posible está dado por una parcialidad (la fuerza hegemónica) que asume la representación de una totalidad mítica. En términos lacanianos, un objeto es elevado a la dignidad de la Cosa (Laclau, 2005: 149).

Pero además, Laclau sostiene que, con la noción de "guerra de posición", Gramsci abrió el camino para pensar un desplazamiento retórico-político e historicista que trasciende el esencialismo inmanente de las identidades del marxismo ortodoxo, y se asimila a la tensión constitutiva (e inerradicable) entre las figuras de la metonimia (sinécdoque) y la metáfora:

La noción gramsciana de guerra de posición, de un desplazamiento político-narrativo gobernada por una lógica del puro evento que trasciende toda identidad preconstituida, anuncia el comienzo de una nueva visión de la historicidad dominada por la tensión -imposible de erradicar- entre metonimia (o sinécdoque) y metáfora (Laclau, 2006: 85).

Para ilustrar la forma de desplazamiento y universalización discursiva que caracteriza a la hegemonía Laclau incluyó en sus textos una serie de categorías intermedias, entre las que se destaca el rol mediador de los significantes vacíos. En el famoso capítulo "¿Por qué los significantes vacíos son importantes para la política?", publicado en Emancipación y diferencia, Laclau articuló al historicismo gramsciano con el rol central de los "significantes vacíos" (Laclau, 1996: 83-84). Los significantes vacíos son fundamentales en la operación hegemónica, ya que se trata de ciertos significantes clave (revolución, justicia, democracia, etc.) que, en determinada coyuntura histórico- 
política, logran "vaciar" su inherente particularismo para universalizar lo social y construir un "orden comunitario", allí donde el mismo estaba ausente. En otros trabajos Laclau definió a estos significantes unificadores como significantes "tendencialmente" vacíos, en el momento en que no existe una lógica de vaciamiento absoluto de la particularidad ${ }^{11}$ (Laclau, 2003b: 209).

Lo cierto es que la lógica de desplazamiento de la clase corporativa en clase hegemónica en la dinámica históricopolítica -que se expresa en términos de lo que Gramsci definía como una "voluntad colectiva"- le permitió a Laclau mostrar una tercera homología conceptual con la forma de universalización relativa de la particularidad que caracteriza a la operación hegemónica ${ }^{12}$.

11 Sobre el concepto de significante vacío, sus antecedentes y sus reformulaciones en la teoría política del discurso de Laclau, véase Montero (2012: 3-6 y ss.).

12 En el artículo "Antagonismo, subjetividad y política" Laclau también construyó lo que podría pensarse como una especie de homología general entre la lógica de la hegemonía y el concepto de "Abgrund" (abismo) de Heidegger (Laclau, 2014a: 146-147 y 150). Sin embargo, en la teoría laclauiana el concepto de Abgrund operaría como "una reflexión propiamente ontológica" que, además, "no se deriva de una experiencia óntica específica" (véase De Mendonca, Freitas Linhares y Barros, 2016, op. cit., p. 181 y ss.). En todo caso, en sus textos Laclau no analizó los usos de este concepto desde el plano óntico y tampoco lo mencionó en otros trabajos centrales de su obra. 


\section{Los usos óntico-fenoménicos de las homologías desde la dinámica histórico-política}

\subsection{El desplazamiento retórico-político de la metonimia a la metáfora en la operación hegemónica}

Como señala Laclau: “No hay significación ontológica que no se construya a través del investimiento de un contenido óntico" (Laclau, 2014a: 142). A su vez, "la articulación entre lo óntico y lo ontológico está siempre mediada discursivamente" (Laclau, 2014a: 142). Dado que en la TPD existe una articulación (sin subsunción ni determinación causal) que ata con fuerza a lo ontológico con lo óntico (Fair, 2019), las homologías que destacamos en los apartados previos son puestas en juego en la dinámica política contingente de la lucha hegemónica. Desde el nivel óntico-fenomenológico Laclau usa los tropos clásicos de la retórica (metonimia y metáfora) -junto con las figuras complementarias de la analogía, la catacresis y la sinécdoquepara mostrar el desplazamiento (tendencial) de la metonimia a la metáfora y de esta última de nuevo a la metonimia en la operación hegemónica. Laclau sostiene que, aunque la lógica de la hegemonía es "metonímica", ya que supone un desplazamiento retórico-político de lo particular a lo universal, cuando "continúa por un cierto período de tiempo", la misma genera un vínculo que es percibido por los agentes como si fuera "natural" (cuando obviamente no lo es). De este modo, al igual que ocurre con la contaminación recíproca que existe entre las lógicas de la equivalencia y de la diferencia, en la dinámica política la metonimia asume la forma (tendencial) de una "analogía" y de una 
"metáfora" de carácter "catacrética". En esas circunstancias, lo particular logra "desplazarse" exitosamente para encarnar simbólicamente el papel del todo (universal) (por lo que se oculta su carácter metonímico) (Laclau, 2002: 3, 2003c, 2005: 141, 2006):

La totalización de un sistema de diferencias es imposible sin una exclusión constitutiva. Sin embargo, esta última tiene, como un efecto lógico primario, la división de todo elemento significativo entre una dimensión equivalencial y una dimensión diferencial. Como estas dimensiones no pueden ser lógicamente suturadas, la consecuencia es que toda sutura será retórica, una cierta particularidad, sin cesar de ser particular, asumirá un cierto rol de significación universal (Laclau, 2008: 21).

A continuación, Laclau superpone el deslizamiento de la figura de la catacresis con el desplazamiento tendencial del objeto pequeño a a la Cosa (la Madre) en la operación hegemónica:

Catacresis $=$ retoricidad $=$ posibilidad misma del sentido. La misma lógica que encontramos en el psicoanálisis entre la Cosa (imposible) y el objeto a la hallamos nuevamente como la condición misma de la significación (Laclau, 2008: 21).

Para mostrar esta lógica de desplazamiento retóricopolítico de la metonimia (particular) a la metáfora (universal) en la disputa hegemónica, en LRP Laclau se refirió al ejemplo de los vínculos históricos y contingentes entre las luchas anti-racistas y sindicales:

Una relación de desplazamiento entre términos, problemas, actores, etc., es lo que se denomina, en retórica, una metonimia. Supongamos que esta conexión entre luchas antirracistas y sindicales continúa por un cierto período de tiempo: en ese caso, la gente va a comenzar a sentir que existe un vínculo natural entre los dos tipos de lucha. Así, la relación de contigüidad va a comenzar a convertirse en una de analogía, la metonimia, en una metáfora (Laclau, 2005: 141). 
Cuando ciertas relaciones particulares permanecen "por un cierto periodo de tiempo", las articulaciones contingentes entre los elementos particulares logran sedimentarse y objetivarse (tendencialmente) como si fueran relaciones "naturales". Sin embargo, sabemos que desde la TPD todas las relaciones entre los elementos son siempre contingentes y relativas. Precisamente, la operación hegemónica intenta que las luchas metonímicas (particulares) logren presentarse retóricamente como si fueran una totalización metafórica (universal):

Las diferentes luchas e iniciativas democráticas no están definidas entre sí por vínculos necesarios, es decir, que nos enfrentamos con relaciones metonímicas de contigüidad. Pero la operación hegemónica intenta, sin embargo, hacer que la condensación de esas luchas sea tan firme y estable como sea posible; aquí la metonimia tiende a presentarse en totalización metafórica (Laclau, 2006: 95).

A partir del "giro deconstructivo" y los aportes de Genette y De Man, en "Política de la retórica" Laclau cuestionó las "principales distinciones objetivas de la ontología antigua", entre las que incluyó "de Aristóteles, a Cicerón y Quintiliano" (Laclau, 2006: 73). El teórico político argentino reconoció la imposibilidad de fijar criterios objetivos y necesarios para analizar las figuras tropológicas y afirmó que, fenoménicamente, existe un "continuum" entre estas figuras retóricas (Laclau, 2006: 74). Pero, luego de destacar la contingencia y el desplazamiento incesante de todo juego de lenguaje, Laclau sostuvo que existe un "criterio de clasificación menos ambiguo" que el continuum, que al mismo tiempo preserva la contingencia radical de lo social. Este criterio consiste en analizar el "grado de fijación" de las figuras tropológicas desde la dinámica política en términos de gradientes relativos (de "más" a "menos") de sedimentación: 
La distinción entre necesidad y contingencia es más prometedora. En este caso, sin que sea enteramente posible evitar el continuum por el que una figura pasa insensiblemente a la otra, tenemos, al menos, un criterio de clasificación menos ambiguo: un discurso será más o menos metafórico dependiendo del grado de fijación que establezca entre sus componentes constitutivos (Laclau, 2006: 74).

El abordaje discursivo del grado de fijación de las figuras retóricas en la dinámica histórico-política permite analizar la "relativa estructuralidad" (Barros, 2002: 23) y la fuerza relativa de sedimentación de lo social que caracteriza a la operación hegemónica. No obstante, como toda fijación hegemónica es siempre precaria, entonces "la necesidad metafórica es contaminada de un modo decisivo por la contingencia metonímica" (Laclau, 2006: 87). Laclau advierte aquí una lógica de desplazamiento y contaminación particular-universal equivalente al de la metonimia y la metáfora, que se extiende a las figuras retóricas de la contigüidad, la analogía y la sinécdoque:

Si la metonimia fuera tan sólo una metonimia, se basaría en una contigüidad que no estaría contaminada por la analogía, en cuyo caso las separaciones literales en el interior de un discurso dado estarían enteramente en control de los límites del movimiento metonímico. Si la analogía dominara incontestada, una totalización completa habría tenido lugar, con lo que la analogía habría sido reducida a identidad y el movimiento tropológico habría cesado. Si la sinécdoque hubiera logrado sustituir al todo por la parte, esto significaría que el todo podría haber sido aprehendido con independencia de la parte (Laclau, 2006: 92).

Fenoménicamente (es decir, a nivel óntico), los tropoi realizan siempre un deslizamiento histórico que se traduce en una contaminación mutua entre las figuras retóricas. Estos movimientos retórico-políticos, homólogos al desplazamiento particular-universal-particular de la operación hegemónica, diluyen toda definición literal/ 
objetiva, rompen con las disyunciones lógicas y con todo fundamento, sustancia o esencia de lo social:

Las condiciones de una retórica cuyos movimientos tropológicos han de ocupar el terreno de un fundamento que no es él mismo fundado, han de encontrarse en la imposibilidad de aceptar la definición literal de cada uno de los tropoi, y en la necesidad de subrayar las lógicas por las cuales cada uno de ellos tiende a diluirse en el otro. Lo mismo ocurre con la hegemonía: las condiciones de su plena operatividad son las mismas que las condiciones de su extinción (Laclau, 2006: 93).

De allí que, aunque la operación hegemónica se presente con mayor o menor grado de éxito como una metáfora de la totalidad, en realidad "la hegemonía es siempre metonímica", en el momento en que "lo que es constitutivo de la relación hegemónica es que los elementos y las dimensiones que le son inherentes están articulados por vínculos contingentes"13 (Laclau, 2006: 74).

\subsection{El desplazamiento discursivo del objeto a (como objeto parcial) a la dignidad de la Cosa (universalidad ausente) en la operación hegemónica}

Al igual que los tropos de la retórica, los conceptos de la teoría lacaniana que utiliza Laclau se encuentran en continuo

13 Aunque en este trabajo nos enfocamos en los aspectos óntico-fenoménicos, la tensión constitutiva que existe en la teoría del discurso de Laclau entre la lógica de la equivalencia y la lógica de la diferencia y entre la particularidad y la universalidad, tiene implicancias directas al nivel normativo (éticopolítico crítico), ya que supone un rechazo político a toda identidad esencialista o fundamentalista (sea religiosa o secular) que procure eliminar la contingencia radical y las diferencias y particularidades sociales. Sobre el particular, véase De Mendonca (2014: 76 y ss.), entre otras/os. 
desplazamiento en la dinámica de la lucha hegemónica. Recordemos que Lacan emplea en su obra nociones de la fenomenología existencialista, a través de Heidegger, Kojeve y Merleau Ponty, incorporando a su esquema estructural la historicidad (Zizek, 2005; Álvarez, 2006: 17, 21). Con el desarrollo de la noción de nudo borromeo, además, Lacan mostró el "devenir de un proceso de articulación compleja que es, simultáneamente, histórico y estructural" (Farrán, 2009: 3).

A partir de las críticas de Zizek (1993), en "Nuevas reflexiones sobre la revolución de nuestro tiempo" Laclau incorporó una distinción analítica entre el antagonismo (simbólico) y la noción de "dislocación" -como análogo al concepto de lo Real de Lacan- para abordar los limites constitutivos y las transformaciones histórico-fenoménicas de la operación hegemónica. Incluyó, además, un uso posestructuralista de las nociones de "sedimentación" y de "reactivación" de la fenomenología existencialista de Heidegger (a través de Husserl). Ello le permitió poner de manifiesto la dinámica de relativa estructuralidad histórica $\mathrm{y}$, a su vez, de dislocación constitutiva de lo social (Laclau, 1993: 50 y ss. ).

En los textos de la última etapa de su obra Laclau (2005, 2008, 2014a) ilustró estos modos de investimiento ónticofenoménico con el ejemplo del objeto a lacaniano y sus modos de desplazamiento (tendencial) a la dignidad de la Cosa. Recordemos que, para Lacan, el objeto petit a, entendido como un objeto causa de deseo, cumple una "función ortopédica" que "viene a obturar la falta, la insoportable condición incompleta (no-toda) del 'sistema' político y de la sociedad, elevando a la categoría de elemento unificador del mismo a una particularidad in-esencial". De allí que "en torno a este 'significante amo', 'significante hegemónico', o 
'punto nodal', se cristalizan las identificaciones que hacen efectiva la interpelación política" (Gutiérrez Vera, 2011: 160).

Laclau, luego de señalar que el acceso a Das Ding (la Cosa) es estructuralmente imposible, destaca que, en los mecanismos exitosos de sublimación, el objeto pequeño a (como objeto parcial causa de deseo), sin dejar de constituir un elemento particular, logra investirse libidinalmente como representante de la imposible totalidad:

La Cosa freudiana (Das Ding) es el objeto que sutura una totalidad, pero que es, no obstante, un objeto imposible, una ilusión retrospectiva que no tiene, por lo tanto, acceso a la representación directa. Es, en consecuencia, un objeto imposible, pero también, un objeto necesario. Su representación, por ende, es sólo posible si un objeto parcial, sin dejar de ser parcial, es investido con el papel de representar a esa imposible totalidad. En palabras de Lacan: la sublimación consiste en elevar un objeto a la dignidad de la Cosa (Laclau, 2014a: 147-148).

Ello implica que un concepto del orden de lo ontológico (la imposibilidad de acceder a la Cosa) se manifiesta en el plano óntico a través del desplazamiento de un determinado objeto parcial (el objeto petit a) que, en ciertas condiciones contextuales, logra investirse fenoménicamente como si fuera una universalidad y "tocar" la plenitud (imposible) de Das Ding ${ }^{14}$ :

He intentado mostrar en La razón populista cómo la lógica de la hegemonía y la del objeto a lacaniano se superponen en buena medida y se refieren ambas a una relación ontológica fundamental, en la cual lo pleno (fullness) sólo puede ser tocado a través de su investimiento en un objeto parcial; que no es una parcialidad dentro de la totalidad, sino una parcialidad que es la totalidad (Laclau, 2008: 20).

14 Así como en una primera etapa Laclau retomaba nociones lacanianas a través de Zizek (1992), en esta etapa última Laclau (2005: 143-147, 2008: 20) se basa en aportes de Joan Copjec (2006). 
Como se puede observar, Laclau construye una relación de homología general entre el objeto a de Lacan y la noción de particularidad (y ambos son situados, a su vez, como equivalentes a la figura de la metonimia ${ }^{15}$ ). Al mismo tiempo, la Cosa se homologa a la imposible universalidad (como metáfora de la totalidad ausente). Desde la dinámica históricopolítica ambos conceptos comparten fenoménicamente el mismo modo de desplazamiento y contaminación discursiva entre la parte y el todo (particular-universal-particular) que caracteriza a la operación hegemónica. De allí que Laclau sostenga que:

Los nombres de la plenitud resultarán siempre del investimiento radical de un valor universal en una cierta particularidad; nuevamente: la elevación de un objeto particular a la dignidad de la Cosa (Laclau, 2008: 26).

Como subraya Laclau en LRP, en la dinámica de la lucha hegemónica el desplazamiento (tendencial) de la particularidad inherente del objeto parcial a una universalidad que lo trasciende, muestra que entre lo ontológico y lo óntico existe un mutuo anudamiento (si bien contingente y no lineal):

Lo particular, lo que en nuestro análisis identificamos como un objeto parcial, ha transformado su propia parcialidad en el nombre de una universalidad que lo trasciende. Es por eso que su función ontológica nunca puede ser reducida a su contenido óntico. Sin embargo, como esta función ontológica solo puede estar presente cuando está vinculada a su contenido óntico, éste se convierte en el horizonte de todo lo que existe: el punto en el cual lo óntico y lo ontológico se funden en una unidad contingente $\mathrm{y}$, sin embargo, inescindible (Laclau, 2005: 280).

15 Aunque una lectura más detenida permite observar que Laclau emplea conceptos diferentes para analizar esta relación. Mientras que en ocasiones señala que la lógica de la hegemonía y la del objeto a es "idéntica", en otros lo matiza para indicar que "se superponen en gran medida". 
Este encadenamiento político-discursivo contingente e inescindible que ata a la función ontológica con sus contenidos óntico-fenoménicos rompe con toda disyunción estricta y tajante entre las lógicas político-discursivas y sus modos de investimiento en la dinámica histórico-política.

\subsection{El desplazamiento discursivo de la clase corporativa (particularista) a la clase hegemónica (como voluntad colectiva) en la operación hegemónica}

Al desplazarse al plano óntico-fenoménico Laclau también retoma y pone en juego herramientas de la teoría de la hegemonía de Gramsci para mostrar el funcionamiento fenomenológico de la operación hegemónica. En "Antagonismo, subjetividad y política" el historiador argentino se basó en las nociones de "clase corporativa" y "clase hegemónica" de Gramsci para mostrar el desplazamiento tendencial de los objetivos particulares a los objetivos universales en la dinámica de la lucha política:

Nuestro tercer ejemplo es el de la 'clase hegemónica' en Gramsci. ¿Qué entiende Gramsci por tal? A la 'clase hegemónica' se opone la clase corporativa, que representa intereses sectoriales en el seno de una totalidad suturada. La clase hegemónica, por el contrario, universaliza de algún modo sus propios objetivos, que pasan así a constituir aquellos de fuerzas sociales más vastas (Laclau, 2014a: 148).

A diferencia del marxismo clásico, que "creía en la noción del proletariado como clase universal", por lo que "el proletariado no necesita universalizar nada" (Laclau, 2014a: 148), en la teoría gramsciana la universalidad hegemónica no supone un dato objetivo, sino que es producto de una 
"construcción contingente" que realiza un "proceso de universalización hegemónica":

Este punto es en el en el que percibimos la originalidad de la intervención gramsciana. Para Gramsci la universalidad no es un dato sino una construcción contingente: se trata de un proceso de universalización hegemónica (Laclau, 2014a: 149).

Laclau nos recuerda que Gramsci partió del análisis histórico-político de las características específicas que asumió la Revolución Rusa y su contraste con el fracaso de la revolución proletaria en Europa occidental. La revolución bolchevique contradijo las tesis clásicas de Marx, al realizar una revolución socialista en un país feudalizado y atrasado (en lugar de un país industrializado y con una burguesía desarrollada, como existía en Europa continental) y liderado por los campesinos (en lugar de por la clase obrera urbana, inexistente en Rusia ${ }^{16}$ ). A partir de este contraste entre la teoría de Marx y los hechos histórico-políticos de octubre de 1917, Gramsci asumió con la noción de hegemonía un momento construccionista radical que superó el apriorismo esencialista de la teoría marxista clásica. En palabras de Laclau:

Gramsci es quien va a extraer las conclusiones de esta heterogeneidad inasimilable a las secuencias de los paradigmas clásicos: la heterogeneidad social requiere un momento de construcción radical y constitutivo, que no viene dictado por ninguna secuencia apriorística. Esto es lo que él llamó hegemonía. Ciertos contenidos son investidos con la función de representar la plenitud ausente de la comunidad (Laclau, 2014a: 149).

Aquí Laclau engarza la particularidad de las luchas sociales con el rol mediador de los significantes vacíos en

16 Sobre la distinción histórica entre Oriente y Occidente en la teoría política gramsciana, véase Thwaites Rey (2008). 
la operación hegemónica. Estos significantes privilegiados permiten, en cierta coyuntura histórica, articular la particularidad inherente con la universalidad ausente y los aspectos ontológicos con sus modos contingentes y no lineales de investimiento óntico-fenoménico:

Ciertos contenidos son investidos con la función de representar la plenitud ausente de la comunidad. Esta plenitud se plasma en lo que hemos llamado significantes vacíos. Pero esa función ontológica de expresar la presencia de una ausencia sólo puede tener lugar a través de un investimiento en un contenido óntico (Laclau, 2014a: 149).

Sin embargo, radicalizando aún más sus argumentos, Laclau sostiene que la teoría gramsciana de la hegemonía también puede ser leída a la luz del giro pragmático, ya que supuso una crítica al determinismo histórico y una primacía de lo político, a través de la articulación contextual y contingente de una "voluntad colectiva":

Un concepto como hegemonía apunta a una lógica que bien puede describirse en términos pragmatistas. Gramsci rompía con una concepción en la cual existían leyes apriorísticas del capitalismo que imponían y dictaban un curso necesario a los sucesos históricos. En contra de ella, defendió aquello que se ha dado en llamar la primacía de la política: la formación pragmática de voluntades colectivas a través de articulaciones contingentes cuyo éxito depende enteramente del contexto (Laclau, 1998: 129).

En este punto Laclau innovó en el campo de la teoría política posfundacional, al redefinir y analizar las principales nociones gramscianas a la luz del giro retórico-político. Como lo destaca el propio pensador argentino:

Pienso que todas las categorías centrales de la teoría gramsciana -guerra de posición, voluntad colectiva, intelectuales orgánicos, Estado integral, bloque histórico, hegemonía- pueden ser leídas retóricamente: ellas circunscriben un espacio de movimientos 
tropológicos que aporta una nueva flexibilidad estratégica al análisis político (Laclau, 2006: 96).

En el marco de esta "flexibilidad estratégica" de las categorías centrales de Gramsci para el análisis políticodiscursivo, en algunos textos de su última etapa Laclau sostiene que, a partir de la noción de "voluntades colectivas", Gramsci no sólo trascendió el clasismo, el determinismo y el mecanicismo del marxismo clásico, sino que además dio un giro hacia un "constructivismo radical":

(...) en Gramsci este desfasaje se superaba en la dirección de un constructivismo radical -los agentes no son clases en el sentido tradicional, sino voluntades colectivas- (Laclau, 2014a: 150).

Esta interpretación retórico-política de la obra gramsciana en clave de "constructivismo radical" converge con el énfasis de Gramsci en los aspectos lingüísticos y con el descubrimiento de un giro en su última etapa, que incorpora mayor cantidad de referencias filológicas y una crítica más radical al objetivismo científico (Frosini, 2007: 193-197).

\section{Reflexiones finales}

En los principales textos de la Teoría Política del Discurso Laclau conceptualizó la lógica de la hegemonía desde el plano ontológico general a través de tres homologías basadas en el uso de figuras de la retórica (el desplazamiento de la metonimia a la metáfora), el psicoanálisis lacaniano (el desplazamiento del objeto a a la Cosa) y la teoría de la hegemonía de Gramsci (el desplazamiento de la clase corporativa a la clase hegemónica o fuerza hegemónica), a las que complementó con figuras retóricas adicionales y conceptos mediadores. Esta construcción conceptual se anuda -de un modo no determinista ni lineal- a las premisas teóricas, 
ontológicas y epistémicas de la perspectiva laclauiana, que asumen la sobredeterminación discursiva, la contingencia e historicidad radical y la negatividad constitutiva de lo social. Al desplazarse al nivel óntico-fenoménico, la Teoría del Discurso de Laclau puso en juego las homologías en la dinámica histórico-política. Ello le permitió mostrar el desplazamiento tendencial y la contaminación discursiva entre la metonimia y la metáfora, el objeto pequeño a y la Cosa y la clase corporativa y la clase hegemónica, que caracterizan a la operación hegemónica. Estos movimientos retórico-políticos son equivalentes a la tensión constitutiva, la mutua imbricación y la contaminación recíproca que existen entre la lógica de la equivalencia y la lógica de la diferencia y entre la particularidad y la universalidad, en el momento en que la lógica discursiva de articulación y universalización de lo particular de la operación hegemónica no puede eliminar el resto inherente de particularidad y diferencialidad que define a la hegemonía sin autodisolverse como tal. De este modo, Laclau puso en evidencia el fuerte anudamiento (sin subsunción ni determinación) que ata a lo ontológico y lo óntico en la teoría de la hegemonía y rompió con cualquier intento de disyunción estricta entre la forma y el contenido y entre las lógicas discursivas y el análisis fenoménico-político contingente en el que se ponen en juego los conceptos y categorías.

Como reflexión final quisiera plantear algunas dudas acerca del grado de "felicidad" (en los términos de Austin) de las homologías generales que construyó Laclau para explicar la forma hegemónica y mostrar su modo de funcionamiento en la dinámica histórico-política concreta. Estas inquietudes responden a ciertas ambigüedades e inconsistencias que observamos en la teoría discursiva de la hegemonía en el plano ontológico. Si la homología con las figuras retóricas 
no presenta mayores inconvenientes, no parece ocurrir exactamente lo mismo y en igual magnitud con el uso de las nociones de la teoría gramsciana y, en menor grado, de la teoría lacaniana. En el primer caso, Laclau reconoce en sus textos las fuertes críticas de Gramsci al objetivismo, el economicismo, el determinismo y el mecanicismo del marxismo ortodoxo y destaca en reiteradas ocasiones la centralidad de la noción gramsciana de hegemonía para el análisis político. Además, el propio Laclau subraya en su última etapa que Gramsci incorpora todo un arsenal de herramientas teóricas que brindan una nueva "flexibilidad estratégica" para el análisis retórico-político. El mismo Laclau no duda en situar a su teoría de la hegemonía como una extensión de la obra gramsciana. En La razón populista, a su vez, vimos que Laclau sostiene que Gramsci realizó una "ruptura epistemológica" que fue "decisiva" para oponerse al "esencialismo". Y en otros trabajos es más radical aún, al ubicar el concepto gramsciano de voluntad colectiva dentro de una posición "constructivista radical". Sin embargo, también debemos tener en cuenta que el historiador argentino (junto con Mouffe) criticó en su texto fundacional lo que definió como el "último reducto esencialista" de Gramsci. Observamos, en este sentido, una inconsistencia -o por lo menos una ambigüedad- entre la ruptura epistemológica y el constructivismo de Gramsci que destaca Laclau, y los cuestionamientos onto-epistemológicos a los restos de esencialismo de la teoría gramsciana de sus textos fundadores del posmarxismo.

En el caso de la teoría lacaniana, además de la enorme influencia de Lacan en la Teoría Política del Discurso y la reapropiación laclauiana de una multiplicidad de conceptos nodales del psicoanalista francés, Laclau y Lacan comparten un mismo status ontológico basado en la primacía del significante sobre el significado (S/s) y 
la centralidad que adquiere el orden significante en la construcción y sobredeterminación de lo social, a través de cadenas de significantes asociadas a múltiples y contingentes significaciones posibles. Ambos pensadores destacan, a su vez, el carácter constitutivo de la alteridad/antagonismos y el componente de dislocación estructural -lo Real, según Lacan-, cuyos efectos dislocadores se manifiestan ónticamente a través de los modos de simbolización y sintomatización del orden significante. Sin embargo, la homología general que construye Laclau entre la lógica del objeto a y el significante vacío en la operación hegemónica entra en tensión con el papel unificador y la supuesta centralidad que -por momentos- le indilga Laclau a la figura del líder en la teoría discursiva del populismo. Además, aunque la lógica de desplazamiento tendencial del objeto pequeño a a la Cosa puede ser asimilada a la función de desplazamiento de los significantes vacíos en la operación hegemónica, encontramos algunas oscilaciones graduales en el modo de conceptualizar dicha lógica en sus principales textos. Por un lado, vimos que Laclau destaca reiteradamente que la lógica del objeto petit a y la Cosa y los significantes vacíos y la hegemonía representan dos lógicas "simplemente idénticas" y en las que existe una "homología profunda". Ello supone otorgarle un definitivo status de identidad vis a vis -y no una mera similitud o analogía- a ambas lógicas político-discursivas. Pero, por otro lado, por momentos el mismo Laclau indica que, en realidad, estas lógicas no serían idénticas en su totalidad y profundamente homólogas entre sí, sino que se superpondrían "en buena medida". Aquí podemos observar un matiz gradual que pondera la asimilación vis a vis entre ambas lógicas discursivas.

Teniendoencuentaestas ambigüedadeseinconsistencias, consideramos que quizás la noción de homología que usa 
con frecuencia Laclau para conceptualizar la lógica políticodiscursiva de la hegemonía debiera ser reemplazada, en estos casos, por la figura retórica de la analogía. Ello para mostrar de un modo un poco más preciso la tensión y contaminación recíproca y la mutua implicación discursiva que existe entre la particularidad y la universalidad y entre la lógica de la equivalencia y la lógica de la diferencia, en la operación hegemónica. De esta manera, además -al desplazarse de la construcción ontológica al análisis anudado de los niveles óntico-fenoménico y ético- político crítico- se podría evitar el riesgo que, en la dinámica concreta de la lucha hegemónica, ciertas identidades y contenidos particulares (de derecha) asuman una forma esencialista, objetivista o fundamentalista que destruya o busque limitar fácticamente las luchas socialistas y democráticas de las clases subalternas (de los/las trabajadores y las minorías sociales y raciales) oprimidas en el capitalismo actual, triture las diferencias y particularidades constitutivas y pretenda eliminar la historicidad y la contingencia radical de lo social.

\section{Referencias}

ÁLVAREZ, Alicia (2006). La teoría de los discursos en Jacques Lacan. Bs. As.: Letra viva.

BARROS, Sebastián (2002). Orden, democracia y estabilidad: Discurso y política en la Argentina entre 1976 y 1991. Alción: Córdoba.

BUENFIL BURGOS, Rosa Nidia (2009). “Retórica: una herramienta para el análisis de discursos educativos", X Congreso Nacional de educación educativa, Veracruz, México, 21 al 25 de septiembre. 
CAVALCANTI ALVES, Ana (2010). “O conceito de hegemonía: de Gramsci a Laclau e Mouffe", Lua Nova, n. 80, 71-96.

COPJEC, Joan (2006). El sexo y la eutanasia de la razón. Bs. As.: Paidós.

DE ÍPOLA, Emilio (2009). “La última utopía. Reflexiones sobre la teoría del populismo de Ernesto Laclau". En Claudia Hilb (comp.). El político y el científico. Ensayos en homenaje a Juan Carlos Portantiero. Bs. As.: Siglo XXI, pp. 197-220.

DE MENDONCA, Daniel (2014). “A impossibilidade da emancipacao: notas a partir da teoria do discurso". En D. de Mendonca y L. Peixoto Rodrigues (orgs.), Pós-Estruturalismo e Teoria Do Discurso. Em torno de Ernesto Laclau. Porto Alegre: Edipucrs, pp. 75-91.

DE MENDONCA, Daniel, De Freitas Linhares, Bianca y Barros, Sebastián (2016). “O fundamento como fundamento ausente' nas ciencias sociais: Heidegger, Derrida e Laclau", Sociologias, v. 18, n. 41, 164-194.

DOR, Joel (1997). Introducción a la lectura de Lacan. Barcelona: Gedisa.

FAIR, Hernán (2014). “Lo ético-político en las democracias contemporáneas. Reflexiones críticas en torno al déficit normativo en la teoría de la hegemonía de Ernesto Laclau", CS, n. 13, 19-46.

FAIR, Hernán (2015). “¿Qué queda del posmarxismo en la teoría de la hegemonía de Ernesto Laclau? Tres etapas histórico-políticas y tres desplazamientos en su concepción normativa", Crítica contemporánea. Revista de Teoría Política, n. 5, 41-81. URL: http://cienciassociales. edu.uy/institutodecienciapolitica/wp-content/uploads/ sites/4/2015/12/Fair.pdf 
FAIR, Hernán (2016). “Democracia, representación política, liderazgos y la cuestión institucional. Discusiones sobre la teoría y práctica de la política en las democracias contemporáneas", Arbor, v. 192. URL: http:/ / arbor.revistas. csic.es/index.php/arbor/article/view/2156

FAIR, Hernán (2019). “La hegemonía en su mutuo anudamiento óntico-ontológico en la teoría política de Ernesto Laclau", Trans/form/ação, v. 42, n. 2.

FARRÁN, Roque (2009). “El concepto pensado como nudo borromeo", Zizek Studyies, v. 3, n.1.

FROSINI, Fabio (2007). “Gramsci y la sociedad. De la crítica de la sociología marxista a la ciencia de la política", Revista Internacional de Sociología, v. 47, 179-199.

GENETTE, Gérard (1989). “Metonimia en Proust”. En Figuras III. Barcelona: Lumen.

GIACAGLIA, Mirta (2012). “Universalismo e particularismo: Emancipacao e democracia na teoria do discurso". En D. de Mendonca y L. Peixoto Rodrigues (orgs.), Pós-Estruturalismo e Teoria Do Discurso. Em torno de Ernesto Laclau. Porto Alegre: Edipucrs, pp. 93-108.

GLYNOS, Jason y Stavrakakis, Yannis (2004). “Encounters of the real kind". En S. Critchley y O. Marchart (comps.). Laclau. A critical reader. Routledge: London-New York.

GLYNOS, Jason, Howarth, David, Norval, Aletta, Howarth, David y Speed, Ewen (2009).

DISCOURSE ANALYSIS: varieties and methods. Great Britain: University of Essex.

GRAMSCI, Antonio (2008a). El materialismo histórico y la filosofía de Benedetto Croce. Bs. As.: Nueva Visión. 
GRAMSCI, Antonio (2008b). Notas sobre Maquiavelo, sobre la política y sobre el Estado moderno. Bs. As.: Nueva Visión. GUTIÉRREZ VERA, Daniel (2011). “Ernesto Laclau: el populismo y sus avatares", Íconos, 40, 151-168.

HILLIS MILLER, Jay (2004). “Taking up a task: momentos of decision in Ernesto Laclau's thought". In Simon Critchley and Oliver Marchart (comps.), Laclau: A critical reader, London-New York: Routledge, pp. 217-226.

LACAN, Jacques (1987). Seminario XI: Los cuatro conceptos fundamentales del psicoanálisis, Bs. As.: Paidós.

LACAN, Jacques (1990). Seminario VII: Laética del psicoanálisis. Bs. As.: Paidós.

LACAN, Jacques (2003). Escritos I. Bs. As.: Siglo XXI.

LACAN, Jacques (2008). Seminario 20: Aún. Bs. As.: Paidós.

LACLAU, Ernesto (1985). “Tesis acerca de la forma hegemónica de la política”. En Julio Labastida (coord.), Hegemonía y alternativas politicas en América Latina. México: UNAM, pp. 19-44.

LACLAU, Ernesto (1993). Nuevas reflexiones sobre la revolución de nuestro tiempo. Bs. As.: Nueva Visión.

LACLAU, Ernesto (1996). “¿Por qué los significantes vacíos son importantes para la política?". En Emancipación y diferencia, Bs. As.: Ariel, pp. 69-86.

LACLAU, Ernesto (1998). “Deconstrucción, pragmatismo, hegemonía”. En Chantal Mouffe (comp.). Deconstrucción y pragmatismo. Bs. As.: Espacios del saber, pp. 97-136.

LACLAU, Ernesto (2002). “El análisis político del discurso: entre la teoría de la hegemonía y la retórica". Entrevista a Ernesto Laclau, De Signis, 1-7. 
LACLAU, Ernesto (2003a). Philosophical roots of Discourse Theory. United Kingdom: mimeo.

LACLAU, Ernesto (2003b). “Identidad y hegemonía: el rol de la universalidad en la constitución de lógicas políticas", "Estructura, historia y lo político" y "Construyendo la universalidad". En Judith Butler, Ernesto Laclau y Slavoj Zizek (comps.). Contingencia, hegemonía y universalidad. Diálogos contemporáneos en la izquierda, México: FCE.

LACLAU, Ernesto (2003c). “Catacresis y metáfora en la construcción de la identidad colectiva", Phronesis, n. 3, v. 9.

LACLAU, Ernesto (2005). La razón populista. Bs. As.: FCE.

LACLAU, Ernesto (2006). "Política de la retórica". En Misticismo, retórica y política. Bs. As.: FCE, pp. 57-100.

LACLAU, Ernesto (2008). Debates y combates. Bs. As.: FCE.

LACLAU, Ernesto (2009). "Populismo: ¿qué nos dice el nombre?". En Francisco Panizza (comp.). El populismo como espejo de la democracia. Bs. As.: FCE, pp. 51-70.

LACLAU, Ernesto (2014a). “Antagonismo, subjetividad y política". En Los fundamentos retóricos de la sociedad. Bs. As.: FCE, pp. 127-153.

LACLAU, Ernesto (2014b). “Articulación y los límites de la metáfora". En Los fundamentos retóricos de la sociedad. Bs. As.: FCE, pp. 69-97.

LACLAU, Ernesto (2014c). “Prefacio a la edición inglesa”. En Los fundamentos retóricos de la sociedad. Bs. As.: FCE, pp. 11-20. LACLAU, Ernesto y Mouffe, Chantal (2004). Hegemonía y estrategia socialista, Bs. As.: FCE.

LAKOFF, George y Johnson, Mark (1998). Metáforas de la vida cotidiana. Madrid: Cátedra. 
MARX, Karl (1997). Introducción general a la crítica de la economía política / 1857. Bs. As.: Siglo XXI.

MARX, Karl y Engels, Friedrich (2001). Manifiesto del Partido Comunista y otros ensayos. Bs. As.: Cs.

MELO, Julián y Aboy Carlés, Gerardo (2014). “La democracia radical y su tesoro perdido. Un itinerario intelectual de Ernesto Laclau", PostData, v. 19, n. 2, 395-427.

MONTERO, Ana Soledad (2012). “Significantes vacíos y disputas por el sentido en el discurso político: un enfoque argumentativo", Identidades, n. 3, v. 2, 1-25.

NORVAL, Aletta (2008). “Las decisiones democráticas y la cuestión de la universalidad". En Simon Critchley y Oliver Marchart (comps.). Laclau. Aproximaciones críticas a su obra, Bs. As.: FCE, pp. 177-208.

STAVRAKAKIS, Yannis (2007a). Lacan y lo político. Bs. As.: Prometeo-UNLP.

STAVRAKAKIS, Yannis (2007b). The lacanian left. Psichoanalysis, theory, politics. Edinburgh: University Press. THWAITES REY, Mabel (2008). “El Estado ampliado en el pensamiento gramsciano". En Mabel Thwaites Rey (comp.). Estado y marxismo. Un siglo y medio de debates. Bs. As.: Prometeo, pp. 129-160.

ZIZEK, Slavoj (1992). El sublime objeto de la ideología. Bs. As.: Siglo XXI.

ZIZEK, Slavoj (1993). "Más allá del análisis del discurso". En Ernesto Laclau, Nuevas reflexiones sobre la revolución de nuestro tiempo. Bs. As.: Nueva visión, pp. 257-267.

ZIZEK, Slavoj (2005). "El objeto a en los lazos sociales", Imago agenda, $\mathrm{s} / \mathrm{d}$. 
Recebido em 05/11/2018

Aprovado em 25/09/2019

\section{Hernán Fair}

E-mail: hernanfair@yahoo.com

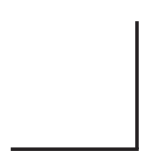

Revista Brasileira de Estudos Políticos | Belo Horizonte | n. 119 | pp. 187-226 | jul./dez. 2019 